\title{
Care reality of menopausal women in Germany: healthcare research using quantitative (SHI claims data) and qualitative (survey) data collection
}

\author{
Petra Stute $^{1}$ D $\cdot$ Helena Eversheim ${ }^{2} \cdot$ Diethe Ortius-Lechner $^{2} \cdot$ Melanie May $^{3} \cdot$ Chiara Feig $^{3}$
}

Received: 30 October 2021 / Accepted: 12 February 2022 / Published online: 7 March 2022

(c) The Author(s) 2022

\begin{abstract}
Purpose The transition from the fertile phase of life to menopause is associated with numerous physical changes. Hormone replacement therapy (HRT), as the most effective and efficient form of drug treatment, involves the use of oestrogens and progestins with the aim of increasing health-related quality of life through symptom reduction, sleep improvement and affect enhancement.

Methods The medical care situation and disease burden of menopausal women was investigated by means of a survey of 1000 women aged 45-60 years on the topics of quality of life, menopause and HRT and a quantitative, longitudinal healthcare study based on an anonymised and age- and sex-adjusted Statutory Health Insurance (SHI) routine data set with approximately four million anonymous insured persons per year.

Results Out of more than half a million women aged 35-70 years, and with statutory health insurance, $(n=613,104), 14 \%$ $(n=82,785)$ had climacteric disorder documented as a first diagnosis in 2014. The proportion of women with the climacteric disorder, who were prescribed HRT on an outpatient basis, was $21 \%$; according to the forsa survey, $50 \%$ of the women surveyed felt moderate to poorly/very poorly informed about treatment options.

Conclusion Findings from the health insurance research conducted with different data sources (survey and SHI claims data) indicate the need for increasing awareness and providing an early and informative education on HRT and its risks and benefits.
\end{abstract}

Keywords Menopause $\cdot$ Hormone replacement therapy $($ HRT $) \cdot$ Forsa survey $\cdot$ Statutory Health Insurance $($ SHI) claims data $\cdot$ Real-world evidence (RWE)

\section{Introduction}

Menopause is the last, spontaneous menstrual period in a woman's life and occurs at an average age of 51 years [1]. Menopause is associated with a decrease in ovarian function, as reflected in the reduced sex steroid biosynthesis. The multi-year transition from the fertile phase of life to

Petra Stute

petra.stute@insel.ch

1 Gynaecological Endocrinology and Reproductive Medicine, University Women's Hospital Inselspital, Friedbuehlstrasse 19, 3010 Bern, Switzerland

2 Besins Healthcare Germany GmbH, Ullsteinhaus, Mariendorfer Damm 3, 12099 Berlin, Germany

3 HGC Healthcare Consultants GmbH, Graf-Adolf-Platz 15, 40213 Düsseldorf, Germany menopause is associated with numerous physical changes [2]. Most symptoms, which occur with varying intensity, are transient in nature [3]. However, the cessation of ovarian function and resulting hormone deficiency, if left untreated, may result in long-term consequences of the disease, such as osteoporosis [4], coronary heart disease [5] and cognitive impairment [6]. The most important acute accompanying symptoms of menopause, some of which severely impair quality of life, include hot flashes and sweating, sleep disturbances, mood swings, depression, fatigue, memory impairment, sexual dysfunction, urogenital complaints, muscle and joint discomfort, weight gain and skin and hair changes [3, 7, 8]. Conventional hormone replacement therapy (HRT), complementary and alternative medicine (CAM) and nonhormonal pharmacotherapy are available for the treatment of the menopausal syndrome. HRT is the most effective treatment modality [9-12] for reducing symptoms such as hot 
flashes, improving sleep quality and decreasing the severity of depression [13, 14].

As a result of the Women's Health Initiative (WHI) study $[15,16]$, the largest prospective randomised placebo-controlled study on HRT, there was a dramatic collapse in the number of HRT prescriptions [17], despite the study's subsequent more precise conclusions [18]. Even though upon closer examination, the supposedly high health risks (cardiovascular disease, breast cancer) conveyed in these studies turned out to be much smaller than perceived by the public $[12,18]$, the proportion of HRT prescribed decreased to less than $10 \%$ and uncertainty among physicians and patients increased [19-22]. However, not prescribing HRT may lead to a higher burden of disease when symptoms remain untreated, thereby reducing the quality of life. Findings stress that this can lead to higher healthcare costs and increased incapacity for work [17, 23-26].

The aim of this healthcare research was to map the medical care situation of menopausal women in Germany and, consequently, investigate the burden of disease. Primary data (survey) and secondary data (Statutory Health Insurance (SHI) claims data) were used for this purpose.

\section{Methods}

\section{Study design and sample}

\section{Menopausal women survey}

The results of a survey of 1000 women aged 45-60 years on the topics of quality of life, menopause and HRT were used to assess the reality of care from the patients' perspective. The survey was conducted from 6 to 12 May 2020, using the online survey panel forsa.omninet. The primary data obtained are representative and can be applied to the overall population of women aged 45-60 in Germany.

\section{SHI claims data}

The healthcare research is based on an anonymised, ageand gender-adjusted SHI claims data set of the Institute for Applied Health Research Berlin GmbH (InGef) with approximately four million insured persons per year and represents a representative sample of approximately six percent of the German population [27]. In a descriptive, retrospective longitudinal study of two consecutive years of observation, care patterns of female patients aged 35-70 with an initial diagnosis of climacteric disorder were mapped over a sixyear period (2013-2018). The study population was divided into cohort 1) patients on HRT and cohort 2) patients not on HRT. Cohort 1) was further subdivided into subgroups based on the respective dosage form of the prescribed HRT. Only those prescriptions issued in the outpatient sector were considered. (Fig. 1). A two-group pre-post study design was used - for cohort 1) observation started after the first coded diagnosis and the follow-up observation started after the first prescription of HRT, whereas for cohort 2) patients were observed both before and after the initial coded diagnosis.

Patients aged 35-70 years were included in this healthcare study based on diagnosis coding according to the ICD-10-German Modification (GM) classification system (Table 1). Patients, who had a climacteric disorder as a confirmed outpatient diagnosis in at least two different quarters in the index year of 2014 (period between Q1 2014 and Q4 2018) or as an inpatient main or secondary diagnosis, were included in this study. It was stipulated that in the 365 days prior to the index period (2014), patients must not have had any of the predefined ICD-10-GM diagnoses documented or received an HRT prescription (baseline). Outpatient prescriptions were considered according to DIMDI ATC classification.

\section{Results}

\section{Patient characteristics (SHI claims data)}

Out of a total of 2,088,941 women with statutory health insurance, 613,104 women aged 35-70 years with and without climacteric disorder as an ICD-10-GM diagnosis were identified in the database in the calendar year 2014. Of these, 82,785 were patients (14\%) with a confirmed initial diagnosis of climacteric disorder (Fig. 2). The administrative incidence in Germany was $4.0 \%$; extrapolated, this corresponds to a total of 1.6 million women.

Patients in this study were identified predominantly by the N95 code (climacteric disorders) $(n=46,969)$. The highest incidence could be observed for the N95 code with 7,661 patients per 100,000 (95\% confidence interval, 95\% CI 7592-7730). The majority of women, who received N95 coding, were between $51-60$ years of age $(48 \% ; n=22,378)$ or older $(61-69$ years; $31 \% ; n=14,477)$ (Table 1). Based on the study population $(n=82,785), 65,625$ patients $(79 \%)$ were assigned to cohort 2) without HRT and 17,160 patients (21\%) were assigned to cohort 1) with HRT. Thus, overall, the majority of patients did not receive HRT. In terms of the choice of HRT (systemic versus vaginal), the distribution was nearly 50:50. When systemic HRT was prescribed, it was primarily oral $(67 \%)$, followed by the transdermal dosage form (26\%) (Fig. 2). 


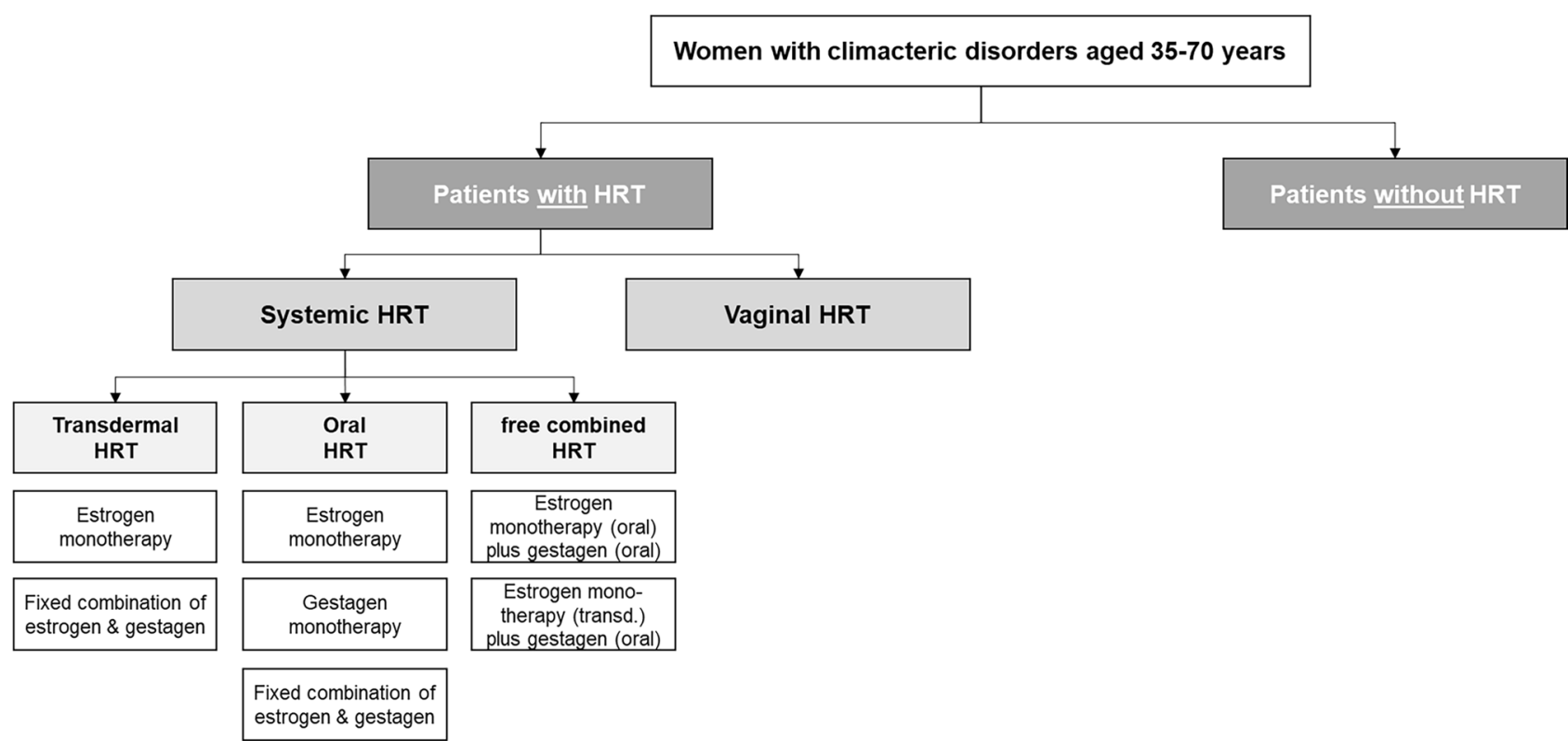

Fig. 1 Classification of Cohort 1) with hormone replacement therapy (HRT) according to systemic (transdermal/oral/free combination1) and vaginal

Table 1 Number and 95\% confidence interval (CI) of patients with specific ICD-10-GM diagnosis at index and stratified per age group

\begin{tabular}{|c|c|c|c|c|c|c|c|c|}
\hline $\begin{array}{l}\text { ICD-10 } \\
\text { Codes }^{1}\end{array}$ & & description & Age group & $\begin{array}{l}\mathrm{N} \text { at risk age } \\
\text { group } 35-70\end{array}$ & $\begin{array}{l}\mathrm{N} \text { with diagnosis } \\
\text { age group } 35-70\end{array}$ & $\begin{array}{l}\mathrm{N} \text { per } 100.000 \\
\text { age group } 35-70\end{array}$ & $95 \%$ UCI & $95 \% \mathrm{LCI}$ \\
\hline N95 & E34.9 & Inclusion criteria (total) & $35-40$ & 87,983 & 10,398 & 11,818 & 11,592 & 12.048 \\
\hline N93 & E28.3 & & $41-45$ & 90,270 & 11,192 & 12,398 & 12,170 & 12,630 \\
\hline $\begin{array}{l}\text { N92 } \\
\text { N91.1 }\end{array}$ & $\begin{array}{l}\text { E28.8 } \\
\text { F289 }\end{array}$ & & $46-50$ & 107,500 & 16,943 & 15,761 & 15,524 & 16,000 \\
\hline N91.2 & E89.4 & & $51-60$ & 178,121 & 27,126 & 15,229 & 15,048 & 15,411 \\
\hline N91.4 & $\mathrm{Z} 90.7^{2}$ & & $61-69$ & 133,717 & 16,043 & 11,998 & 11,813 & 12,185 \\
\hline N91.5 & & & 70 & 15,513 & 1083 & 6981 & 6572 & 7410 \\
\hline & & & Total & 613,104 & 82,785 & 13,503 & 13,411 & 13,595 \\
\hline N95 & & Climacteric disorder as & $35-40$ & 87,983 & 313 & 356 & 317 & 397 \\
\hline & & primary diagnosis & $41-45$ & 90,270 & 1547 & 1714 & 1629 & 1801 \\
\hline & & & $46-50$ & 107,500 & 7270 & 6763 & 6,608 & 6920 \\
\hline & & & $51-60$ & 178,121 & 22,378 & 12,563 & 12,399 & 12,729 \\
\hline & & & $61-69$ & 133,717 & 14,477 & 10,827 & 10,651 & 11,004 \\
\hline & & & 70 & 15,513 & 984 & 6343 & 5953 & 6752 \\
\hline & & & Total & 613,104 & 46,969 & 7661 & 7592 & 7730 \\
\hline
\end{tabular}

${ }^{1}$ N95 Climacteric disorder, N93 Other abnormal uterine or vaginal bleeding, N92 Menstruation that is too heavy, too frequent, or irregular, N91.1 Secondary amenorrhea, N91.2 Amenorrhea, unspecified, N91.4 Secondary oligomenorrhea, N91.5 Oligomenorrhea, unspecified, E34.9 Endocrine disorder, unspecified, E28.3 Primary ovarian failure, E28.8 Other ovarian dysfunction, E28.9 Other ovarian dysfunction, E89.4 Ovarian failure after medical measures, Z90.7 Loss of one or more genital organs

${ }^{2}$ Factors that influence the state of health and lead to the use of the health system

\section{Disease burden}

\section{Menopausal women survey}

In the forsa survey, two-thirds of women between the ages of 45 and 60 said they felt their quality of life was impaired by menopausal symptoms. One in seven women (14\%) even felt severely restricted. More than a third of women living in Germany (37\%) said that their health had become worse/ much worse during perimenopause. Hot flashes (72\%), sleep disturbances $(51 \%)$, mood swings (38\%), dry skin/mucous membranes (38\%), and exhaustion (32\%) were among the 


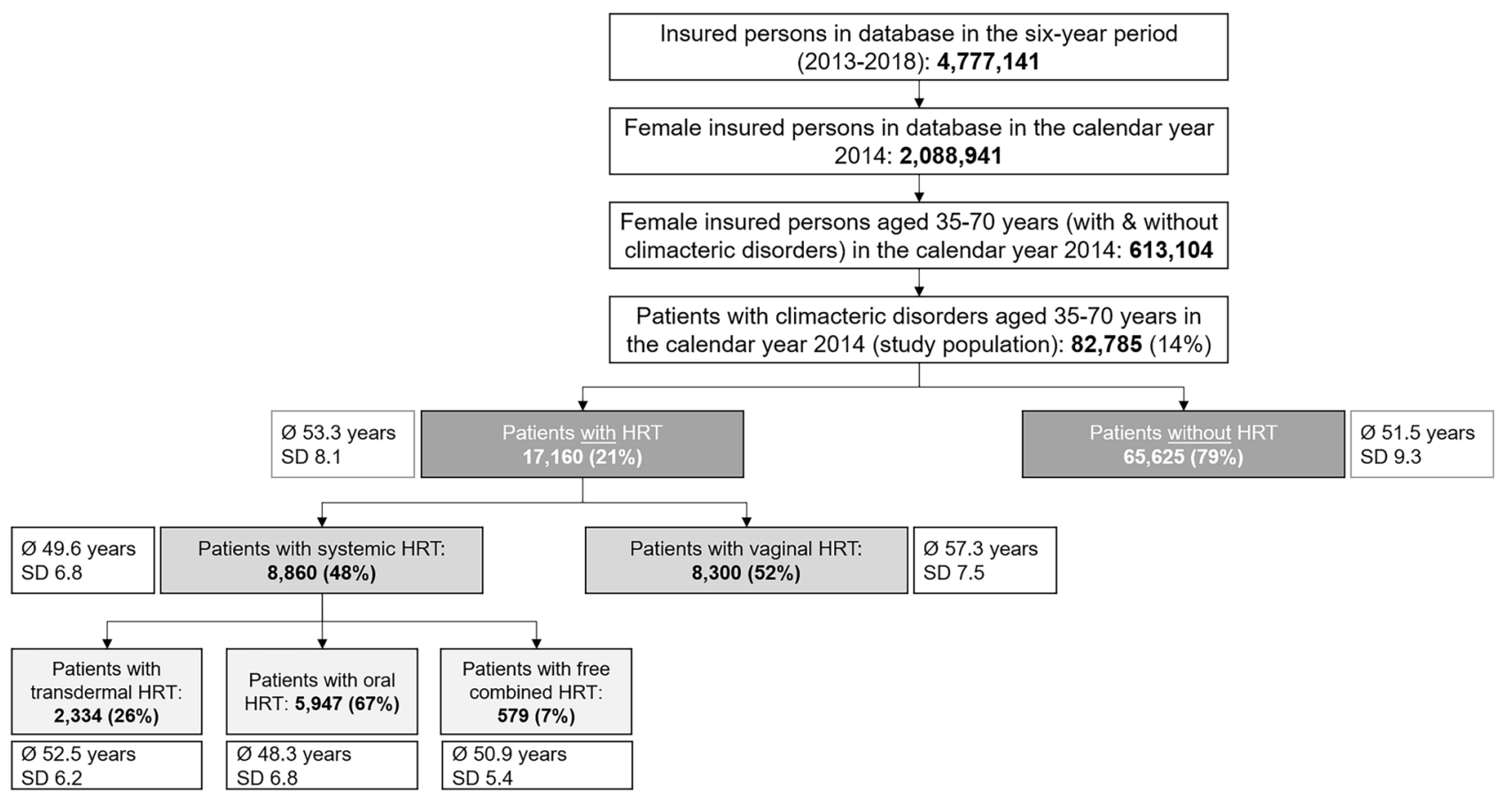

Fig. 2 Sample description based on a patient flow diagram

most common complaints. Despite this, $68 \%$ of women did not consider HRT until their symptoms became acute (Table 2).

\section{SHI claims data}

Predefined concomitant diseases as well as climacteric complaints were investigated. Based on the total collective ( $n=82,619), 49.3 \%$ of patients $(n=40,695)$ suffered from depressive disorders and/or behavioural disorders (F40F45/F32-F33) and 36.2\% $(n=29,867)$ from musculoskeletal disorders (M80-M81/M05-M19) during the two-year follow-up period. Regarding the studied complaints, which were based on the categories of the Menopause Rating Scale (MRS) II $(1,29)$, back pain (M54) with 54.1\% ( $n=44,697)$, conditions related to the menopause, such as hot flashes, insomnia, headache and lack of concentration (N95.1), with $21.8 \%(n=18,043)$, reactions to severe stress and adjustment disorders (F43) with 17.5\% $(n=14,422)$, joint pain (M25.5) with $15.4 \%(n=12,690)$, sleep disorders $(\mathrm{G} 47)$ with $11.5 \%$ $(n=9515)$ and migraine (G43) with $11.2 \%(n=9278)$ were among the most common physical and psychological complaints. The proportion of patients with each concomitant condition was higher in cohort 1) with HRT. In this cohort, the proportion of patients with N95.1 coding decreased from $22.4 \%(n=3838)$ in the first year of observation to $21.5 \%$ $(n=3692)$ in the second year of observation. The whole cohort shows $12.0 \%$ at baseline and $16.5 \%$ in the follow-up prescriptions of psychoanaleptics (incl. antidepressants etc.), with 15.3 and $21.7 \%$, respectively, in the cohort with HRT and 11.1 and $15.2 \%$, respectively, in the cohort without HRT. During the follow-up period, $45.5 \%$ of the whole cohort had a psychological examination, which comprised $58.0 \%$ of the cohort with HRT and $42.3 \%$ of the cohort without HRT.

\section{Change of physician}

\section{Menopausal women survey}

More than one-third of the women (37\%) felt that their gynaecologist provided mediocre or poor/very poor advice on menopause. With regard to therapies, $50 \%$ felt moderately or poorly/very poorly informed.

\section{SHI claims data}

The majority of patients with and without HRT (75\% in each case) did not change their general practitioner or gynaecologist before a diagnosis of the climacteric disorder (baseline). Based on the cohort with HRT, the proportion of patients, who changed their gynaecologist at least once or twice, increased in the first year of follow-up ( 1 change $=43 \%$; 2 changes $=14 \% ; \geq 3$ changes $=6 \%$ ). This is significantly higher than the observed switching frequency in the cohort without HRT (1 switch $=36 \% ; 2$ switches $=7 \% ; \geq 3$ switches $=2 \%$ ) (Fig. 3). Family physicians, on the other hand, were changed less in both the cohort with HRT and the cohort without HRT over the observation period. HRT 


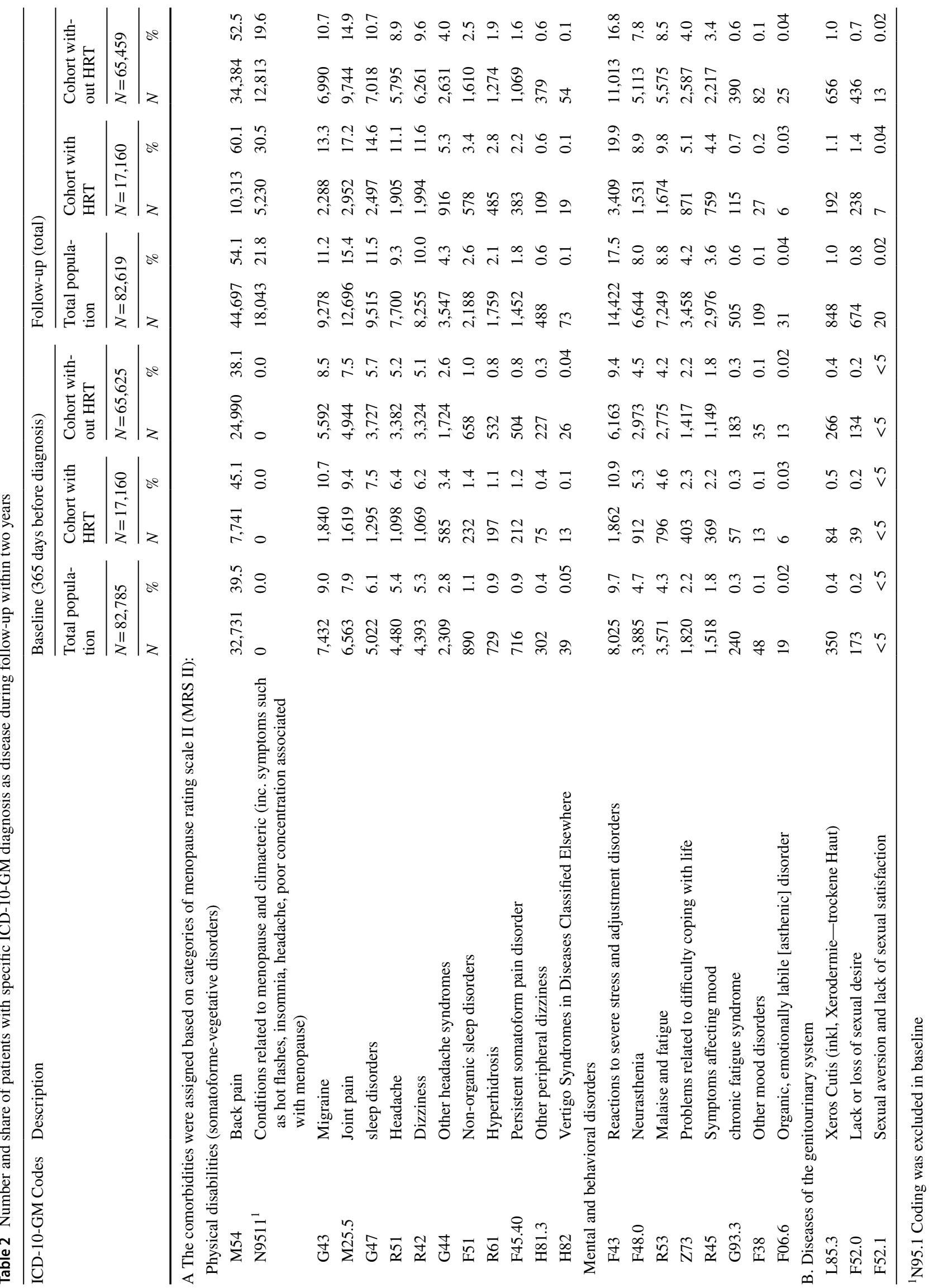




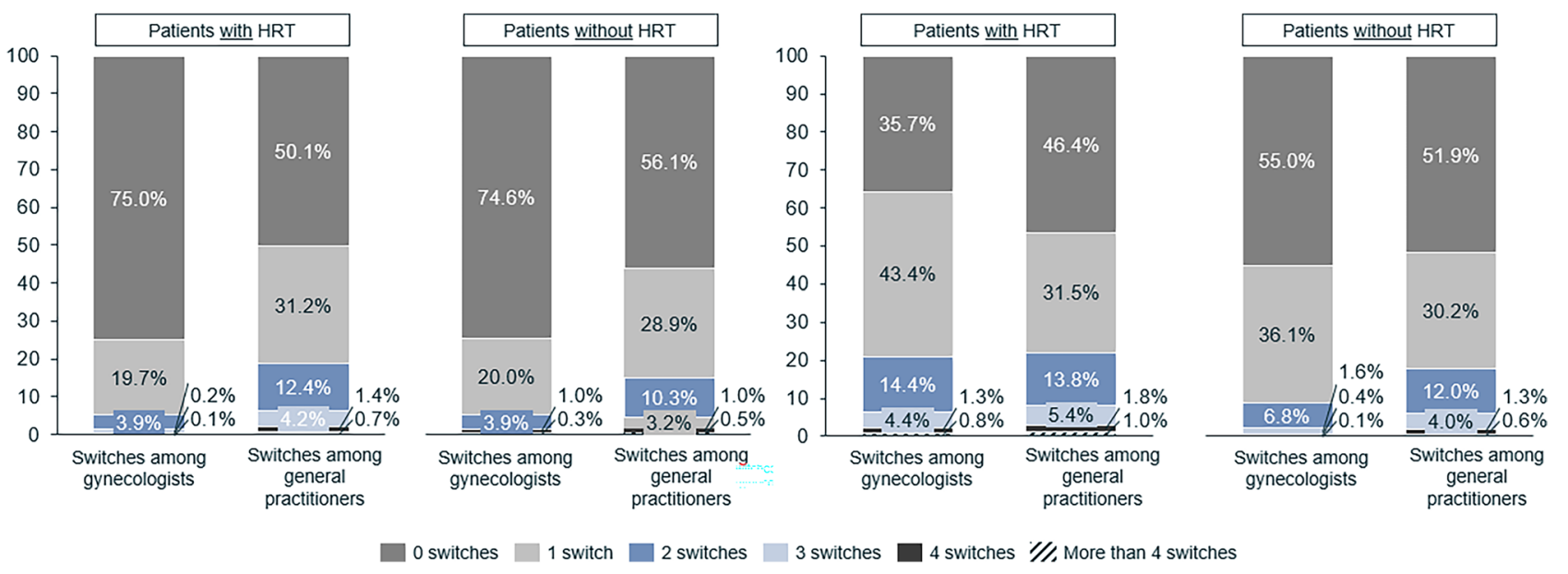

\begin{tabular}{|c|c|c|c|c|c|c|c|c|c|}
\hline & \multirow[b]{5}{*}{ Number of switches } & \multirow{2}{*}{\multicolumn{4}{|c|}{ Baseline (before Index) }} & \multirow{2}{*}{\multicolumn{4}{|c|}{ First Follow-up year }} \\
\hline & & & & & & & & & \\
\hline & & \multicolumn{2}{|c|}{$\begin{array}{l}\text { Number (N) with switch at } \\
\text { gynecologist (AGS 15-17) }\end{array}$} & \multicolumn{2}{|c|}{$\begin{array}{l}\text { Number (N) with switch at GP } \\
\text { (AGS 01-03) }\end{array}$} & \multicolumn{2}{|c|}{$\begin{array}{l}\text { Number (N) with switch at } \\
\text { gynecologist (AGS 15-17) }\end{array}$} & \multicolumn{2}{|c|}{$\begin{array}{l}\text { Number (N) with switch at GF } \\
\text { (AGS 01-03) }\end{array}$} \\
\hline & & \multicolumn{2}{|c|}{$\mathrm{N}=17,160$} & \multicolumn{2}{|c|}{$N=17,160$} & \multicolumn{2}{|c|}{$N=17,160$} & \multicolumn{2}{|c|}{$N=17,160$} \\
\hline & & $\mathrm{N}$ & $\%$ & $\mathrm{~N}$ & $\%$ & $\mathrm{~N}$ & $\%$ & $\mathrm{~N}$ & $\%$ \\
\hline \multirow{6}{*}{ Cohort with HRT } & 0 & 12,870 & $75.0 \%$ & 8,593 & $50.1 \%$ & 6,124 & $35.7 \%$ & 7,963 & $46.4 \%$ \\
\hline & 1 & 3,380 & $19.7 \%$ & 5,347 & $31.2 \%$ & 7,448 & $43.4 \%$ & 5,409 & $31.5 \%$ \\
\hline & 2 & 665 & $3.9 \%$ & 2,136 & $12.4 \%$ & 2,476 & $14.4 \%$ & 2,374 & $13.8 \%$ \\
\hline & 3 & 189 & $1.1 \%$ & 729 & $4.2 \%$ & 748 & $4.36 \%$ & 919 & $5.4 \%$ \\
\hline & 4 & 31 & $0.2 \%$ & 242 & $1.4 \%$ & 230 & $1.3 \%$ & 316 & $1.8 \%$ \\
\hline & More than 4 switches & 25 & $0.1 \%$ & 113 & $0.7 \%$ & 134 & $0.8 \%$ & 179 & $1.0 \%$ \\
\hline
\end{tabular}

\begin{tabular}{|c|c|c|c|c|c|c|c|c|c|}
\hline & & \multicolumn{4}{|c|}{ Baseline (before Index) } & \multicolumn{4}{|c|}{ First Follow up year } \\
\hline & & \multicolumn{2}{|c|}{$\begin{array}{l}\text { Number (N) with switch at } \\
\text { gynecologist (AGS 15-17) }\end{array}$} & \multicolumn{2}{|c|}{$\begin{array}{l}\text { Number (N) with switch at GP } \\
\text { (AGS 01-03) }\end{array}$} & \multicolumn{2}{|c|}{$\begin{array}{l}\text { Number (N) with switch at } \\
\text { gynecologist (AGS 15-17) }\end{array}$} & \multicolumn{2}{|c|}{$\begin{array}{c}\text { Number (N) with switch at GP } \\
\text { (AGS 01-03) }\end{array}$} \\
\hline & & \multicolumn{2}{|c|}{$\mathrm{N}=65,625$} & \multicolumn{2}{|c|}{$\mathrm{N}=65,625$} & \multicolumn{2}{|c|}{$\mathrm{N}=65,459$} & \multicolumn{2}{|c|}{$\mathrm{N}=65,459$} \\
\hline & Number of switches & $\mathrm{N}$ & $\%$ & $\mathrm{~N}$ & $\%$ & $\mathrm{~N}$ & $\%$ & $\mathrm{~N}$ & $\%$ \\
\hline \multirow{6}{*}{ Cohort without HRT } & 0 & 48,982 & $74.6 \%$ & 36,804 & $56.1 \%$ & 36,016 & $55.0 \%$ & 33,953 & $51.9 \%$ \\
\hline & 1 & 13,147 & $20.0 \%$ & 18,966 & $28.9 \%$ & 23,646 & $36.1 \%$ & 19,761 & $30.2 \%$ \\
\hline & 2 & 2,563 & $3.9 \%$ & 6,768 & $10.3 \%$ & 4,442 & $6.8 \%$ & 7,885 & $12.0 \%$ \\
\hline & 3 & 642 & $1.0 \%$ & 2,112 & $3.2 \%$ & 1,025 & $1.6 \%$ & 2,638 & $4.0 \%$ \\
\hline & 4 & 200 & $0.3 \%$ & 653 & $1.0 \%$ & 236 & $0.4 \%$ & 825 & $1.3 \%$ \\
\hline & More than 4 switches & 91 & $0.1 \%$ & 322 & $0.5 \%$ & 94 & $0.1 \%$ & 397 & $0.6 \%$ \\
\hline
\end{tabular}

${ }^{1}$ The examination of switches within the two specialist groups was carried out on the basis of the lifelong doctor number ("Lebenslange Artznummer" LANR), a nine-digit number that the responsible Association of Statutory Health Insurance Physicians gives to every doctor and psychotherapist nationwi

Fig. 3 Proportion of patients and number of physician changes* (within the specialty group of gynaecologists and family physicians) at baseline (left) and in the first year of follow-up (right)

was prescribed on average $1 \frac{1 / 2}{2}$ years after diagnosis. The use of systemic HRT (MW 15.9; SD 14.9 months) was started earlier compared with vaginal HRT (MW 19.5; SD 16.2 months). Patients receiving systemic HRT (MW 49.6; SD 6.8 years) were significantly younger than women receiving vaginal HRT (MW 57.3; SD 7.5 years) (Fig. 2).

\section{Incapacity for work (AU)}

\section{SHI claims data}

Climacteric disorders were not considered an obligatory incapacity for work (AU) diagnosis. The proportion of employed women with at least one day of certified incapacity for work during the two-year follow-up period was $36.3 \%$ in women without ICD-10 coding of climacteric disorder, while the proportion of patients with the coded climacteric disorder was $41.0 \%$. The average number of days of sick leave in the first year of observation in women without coded climacteric disorder was 26.5 (SD 42.0), and is thus comparable to the 28.0 days (SD 43.1) in patients with coded climacteric disorder. With respect to sickness benefits (AU for $>6$ weeks), the overall proportion of patients with the coded climacteric disorder was $6.1 \%$ during the 2-year follow-up period, which was higher than the $4.9 \%$ for the group of women without the coded climacteric disorder. A top-5 ranking of AU diagnoses showed that back pain (M54) was among the most common conditions to be substantiated. In 
the first year of observation, the proportion was 3.7\% in the female group without coded climacteric disorder and 5.0\% in female patients overall.

\section{Therapies and costs}

\section{SHI claims data}

Overall, agents from the group of antiphlogistics and antirheumatics (M01) were prescribed in $47.5 \%$ of the total collective of patients with the coded climacteric disorder $(n=39,280)$, followed by analgesics (N02) with $31.4 \%$ $(n=25,978)$ and psychoanaleptics (N06 incl. SRRIs and SNRIs) with $16.5 \%(n=13,670)$. In addition, $45.5 \%$ $(n=37,614)$ of patients were receiving outpatient psychotherapeutic treatment during the two-year follow-up period.

Total costs per patient were slightly lower for the cohort without HRT (observation year 1: 2,220.01 euros p.a.; observation year 2: 2300.65 euros p.a.) compared to the cohort with HRT (observation year 1: 2497.56 euros p.a.; observation year 2: 2501.07 euros p.a.). However, higher medication costs per patient were recorded in the cohort without HRT (observation year 1: 551.21 euros p.a.; observation year 2: 586.91 euros p.a.) compared to the cohort with HRT (observation year 1: 531.04 euros p.a.; observation year 2: 566.20 euros p.a.).

\section{Discussion}

The linking of primary data (survey) with SHI claims data (secondary data) used in this study allows a comprehensive insight into the care of menopausal women since the patient perspective is included in the holistic view in addition to the documented diagnoses and services provided. The use of SHI claims data is associated with specific limitations since the informative value depends not only on the differentiability of the underlying coding system, but also on the coding quality in everyday clinical practice. For this reason, in addition to the specific N95 code (climacteric disorders), other ICD-10-GM diagnoses were considered to help identify menopausal women, to avoid overlooking any patients, if possible. In the quantitative study, the majority of the patients aged 51-69 years were identified by N95 coding. The study conducted by the Central Institute for Statutory Health Care in Germany confirmed that in $45.3 \%$ of cases menopausal symptoms were most frequently billed via N95 in gynaecology practices [28]. Nevertheless, the N92 code ("Menstruation too heavy, too frequent or irregular") also plays an important role in identifying younger patients (26\%; $n=21,889$ ), although it is not possible to determine from the coding alone whether the diagnosis is a true perimenopausal diagnosis or whether the cases coded with N92 are related to other diseases (e.g. hormonal disorders, oncological diseases).

Findings from the epidemiological data collection show that out of more than half a million women aged 35-70 years, and with statutory health insurance, $(n=613,104), 14 \%$ $(n=82,785)$ had menopausal disorders documented as a first diagnosis in 2014. Considering that, according to the forsa survey, two-thirds of women aged 45-60 feel that their quality of life is impaired by menopausal symptoms, a high discrepancy can be observed, which would suggest undercoding or miscoding.

Although there are methodological flaws in the WHI study [6-8], there has been a marked uncertainty and change in prescribing behavior among practitioners that continues to persist [20]. It is therefore not surprising that, according to our evaluation, only $21 \%$ of patients receive HRT despite their menopausal symptoms and that they also have to "wait" about 18 months for it. Even though the proportion with HRT increases in the patient group with exclusive N95 coding (37\%), the data suggest an existing underuse. This proportion is comparable to the Robert Koch Institute DEGS1 study, in which $35.5 \%$ of women reported using HRT [28]. It should be noted that SHI claims data only capture services that were billed through SHI; completeness of data is thus limited since there will be medical services provided that are not billed through SHI (e.g. OTC preparations, hormone magistral prescriptions) [29]. In addition, combination therapies of systemic and vaginal HRT were not investigated in this study.

Based on the SHI claims data and the forsa survey, the female patient population may experience a higher burden of disease, if symptoms remain untreated. In addition to mental disorders, musculoskeletal diseases also play an important role. The high level of suffering is evident from the concomitant illnesses that are closely related to the use of psychotherapy. In addition, $21.8 \%$ of patients suffered from conditions related to menopause and climacteric (N95.1). The high prevalence of comorbid psychological disorders and other pain syndromes suggests the need for comprehensive treatment options, especially since it is known that in patients with menopausal/vasomotor symptoms (VMS), the benefits of HRT generally outweigh the comparatively small risks associated with it [7,9]. Nevertheless, according to the survey, most women (68\%) do not consider the possibility of HRT until symptoms become acute. In addition, 50\% of the women surveyed felt only moderately to poorly/very poorly informed about treatment options. The increased need for information could also be due to the ongoing discussion about the (breast) cancer risk under HRT. The suffering is reinforced by the prescription of specific concomitant medications (analgesics and psychoanaleptics). In particular, 
higher medication costs per patient (p.a.) were recorded in the cohort without HRT. Also, for example, in the American study by Sarrel et al. [23], women with untreated VMS showed not only significantly higher direct costs per patient (MW 1,346 US dollars p.a.) and higher indirect costs (57\% loss of productivity) but also a significantly higher utilisation of healthcare resources ( $82 \%$ higher for all physician visits; $121 \%$ for VMS-related physician visits) than women in the control cohort.

In conclusion, it can be assumed that the long period without therapy and the increased number of changes in physicians are due, among other things, to the general uncertainty on the part of patients and physicians, existing gaps in information about therapy options, the patient's wish to obtain a second medical opinion, the woman's inner psychological conflicts, the initial use of herbal preparations and the increase in complaints in the period after diagnosis. Findings from healthcare research point to the need for increasing awareness and providing early and informative education on HRT. Especially since, according to current knowledge, untreated menopausal symptoms are associated with higher healthcare costs [17, 23, 24], a decrease in work productivity $[17,23,25,26,30]$ and increased physician visits $[23,25,26])$.

Acknowledgements The authors would like to thank Ms C. Härtli for formatting the manuscript.

Author contributions PS: study design, data interpretation, editing and translating the manuscript. HE: study design, data interpretation, financing. DO-L: study design, data interpretation, financing. MM: study design, data analysis. CF: study design, data analysis, writing the first draft of the manuscript.

Funding Besins Healthcare Germany GmbH.

\section{Declarations}

Conflict of interest Prof. Stute MD is employed by Inselspital Bern and received fees for consulting work from Besins Healthcare Germany GmbH. Ms May and Ms Feig are employed by HGC Healthcare Consultants $\mathrm{GmbH}$ and received honoraria for consulting work from Besins Healthcare Germany GmbH. Dr Eversheim and Dr OrtiusLechner are employed by Besins Healthcare Germany $\mathrm{GmbH}$.

Author statement The longitudinal study was conducted by HGC Healthcare Consultants $\mathrm{GmbH}$ with financial support from Besins Healthcare Germany GmbH. The health services research was conducted and analysed by HGC Healthcare Consultants $\mathrm{GmbH}$ and the Institute for Applied Health Research Berlin GmbH (InGef) in agreement with all authors and according to the study protocol. On behalf of fischerAppelt, relations GmbH, forsa Politik und Sozialforschung $\mathrm{GmbH}$ conducted a representative survey (forsa survey) on the topic of "menopause". As part of the survey, a total of 1000 women between the ages of 45 and 60 , who had been selected using a systematic random procedure, were interviewed. The results obtained can only be transferred to the sum total of women between 45 and 60 years of age with the error tolerances possible in all sample surveys (in the present case, \pm 3 percentage points)

Open Access This article is licensed under a Creative Commons Attribution 4.0 International License, which permits use, sharing, adaptation, distribution and reproduction in any medium or format, as long as you give appropriate credit to the original author(s) and the source, provide a link to the Creative Commons licence, and indicate if changes were made. The images or other third party material in this article are included in the article's Creative Commons licence, unless indicated otherwise in a credit line to the material. If material is not included in the article's Creative Commons licence and your intended use is not permitted by statutory regulation or exceeds the permitted use, you will need to obtain permission directly from the copyright holder. To view a copy of this licence, visit http://creativecommons.org/licenses/by/4.0/.

\section{References}

1. McKinlay SM (1996) The normal menopause transition: an overview. Maturitas 23(2):137-145. https://doi.org/10.1016/03785122(95)00985-x

2. Davis SR, Lambrinoudaki I, Lumsden M, Mishra GD, Pal L, Rees $\mathrm{M}$ et al (2015) Menopause. Nat Rev Dis Primers 1:15004. https:// doi.org/10.1038/nrdp.2015.4

3. Woods NF, Mitchell ES (2005) Symptoms during the perimenopause: prevalence, severity, trajectory, and significance in women's lives. Am J Med 118(Suppl 12B):14-24. https://doi.org/10. 1016/j.amjmed.2005.09.031

4. Manolagas SC (2013) Steroids and osteoporosis: the quest for mechanisms. J Clin Invest 123(5):1919-1921. https://doi.org/10. 1172/JCI68062

5. Mosca L, Benjamin EJ, Berra K, Bezanson JL, Dolor RJ, LloydJones DM et al (2011) Effectiveness-based guidelines for the prevention of cardiovascular disease in women-2011 update: a guideline from the american heart association. Circulation 123(11):1243-1262. https://doi.org/10.1161/CIR.0b013e3182 Ofaaf8

6. Zhu D, Montagne A, Zhao Z (2021) Alzheimer's pathogenic mechanisms and underlying sex difference. Cell Mol Life Sci 78(11):4907-4920. https://doi.org/10.1007/s00018-021-03830-w

7. Dennerstein L, Dudley EC, Hopper JL, Guthrie JR, Burger HG (2000) A prospective population-based study of menopausal symptoms. Obstet Gynecol 96(3):351-358

8. Freeman EW, Sammel MD, Lin H, Nelson DB (2006) Associations of hormones and menopausal status with depressed mood in women with no history of depression. Arch Gen Psychiatry 63(4):375-382. https://doi.org/10.1001/archpsyc.63.4.375

9. (2017) The 2017 hormone therapy position statement of The North American Menopause Society. Menopause 24(7):728-53. https://doi.org/10.1097/GME.0000000000000921

10. Stute P, Spyropoulou A, Karageorgiou V, Cano A, Bitzer J, Ceausu I et al (2020) Management of depressive symptoms in peri- and postmenopausal women: EMAS position statement. Maturitas 131:91-101. https://doi.org/10.1016/j.maturitas.2019. 11.002

11. Armeni E, Lambrinoudaki I, Ceausu I, Depypere H, Mueck A, Perez-Lopez FR et al (2016) Maintaining postreproductive health: a care pathway from the European Menopause and Andropause Society (EMAS). Maturitas 89:63-72. https://doi.org/10.1016/j. maturitas.2016.04.013

12. Inwald EC, Albring $C$, Baum E, Beckermann $M$, Bühling KJ, Emons G et al (2021) Perimenopause and 
Postmenopause-Diagnosis and Interventions. Guideline of the DGGG and OEGGG (S3-Level, AWMF Registry Number 015062, September 2020). Geburtshilfe Frauenheilkd 81(6):612-636. https://doi.org/10.1055/a-1361-1948

13. Schneider HPG, Birkhäuser M (2017) Quality of life in climacteric women. Climacteric 20(3):187-194. https://doi.org/10.1080/ 13697137.2017.1279599

14. Utian WH, Woods NF (2013) Impact of hormone therapy on quality of life after menopause. Menopause 20(10):1098-1105. https:// doi.org/10.1097/GME.0b013e318298debe

15. Rossouw JE, Anderson GL, Prentice RL, LaCroix AZ, Kooperberg C, Stefanick ML et al (2002) Risks and benefits of estrogen plus progestin in healthy postmenopausal women: principal results from the Women's Health Initiative randomized controlled trial. JAMA 288(3):321-333

16. Anderson GL, Limacher M, Assaf AR, Bassford T, Beresford SA, Black $\mathrm{H}$ et al (2004) Effects of conjugated equine estrogen in postmenopausal women with hysterectomy: the Women's Health Initiative randomized controlled trial. JAMA 291(14):1701-1712. https://doi.org/10.1001/jama.291.14.1701

17. Manson JE, Kaunitz AM (2016) Menopause management-getting clinical care back on track. N Engl J Med 374(9):803-806. https:// doi.org/10.1056/NEJMp1514242

18. Ameye L, Antoine C, Paesmans M, de Azambuja E, Rozenberg $S$ (2014) Menopausal hormone therapy use in 17 European countries during the last decade. Maturitas 79(3):287-291. https://doi. org/10.1016/j.maturitas.2014.07.002

19. Sturmberg JP, Pond DC (2009) Impacts on clinical decision making - changing hormone therapy management after the WHI. Aust Fam Physician 38(4):249-251 (53-5)

20. Bush TM, Bonomi AE, Nekhlyudov L, Ludman EJ, Reed SD, Connelly MT et al (2007) How the Women's Health Initiative (WHI) influenced physicians' practice and attitudes. J Gen Intern Med 22(9):1311-1316. https://doi.org/10.1007/ s11606-007-0296-Z

21. Thunell L, Milsom I, Schmidt J, Mattsson LA (2006) Scientific evidence changes prescribing practice-a comparison of the management of the climacteric and use of hormone replacement therapy among Swedish gynaecologists in 1996 and 2003. BJOG 113(1):15-20. https://doi.org/10.1111/j.1471-0528.2005.00805.x
22. Kaplan B, Yogev Y, Orvieto R, Hirsch M, Fisher M, Rabinerson D (2004) Effect of the WHI study on the attitude of Israeli gynecologists to hormonal therapy during menopause. Clin Exp Obstet Gynecol 31(4):267-268

23. Sarrel P, Portman D, Lefebvre P, Lafeuille MH, Grittner AM, Fortier J et al (2015) Incremental direct and indirect costs of untreated vasomotor symptoms. Menopause 22(3):260-266. https://doi.org/ 10.1097/GME.0000000000000320

24. Tang WY, Grothe D, Keshishian A, Morgenstern D, Haider S (2018) Pharmacoeconomic and associated cost savings among women who were prescribed systemic conjugated estrogens therapy compared with those without menopausal therapy. Menopause 25(5):493-499. https://doi.org/10.1097/GME.0000000000001028

25. Whiteley J, Wagner JS, Bushmakin A, Kopenhafer L, Dibonaventura M, Racketa J (2013) Impact of the severity of vasomotor symptoms on health status, resource use, and productivity. Menopause 20(5):518-524. https://doi.org/10.1097/GME.0b013 e31827d38a5

26. Whiteley J, DiBonaventura M, Wagner JS, Alvir J, Shah S (2013) The impact of menopausal symptoms on quality of life, productivity, and economic outcomes. J Womens Health (Larchmt) 22(11):983-990. https://doi.org/10.1089/jwh.2012.3719

27. Andersohn F, Walker J (2016) Characteristics and external validity of the German Health Risk Institute (HRI) Database. Pharmacoepidemiol Drug Saf 25(1):106-109. https://doi.org/10.1002/ pds.3895

28. Krause L, Prutz F (2020) Gynaecology and general practitioner services utilisation by women in the age group 50 years and older. J Health Monit 5(2):15-25. https://doi.org/10.25646/6808

29. March S (2017) Individual data linkage of survey data with claims data in germany-an overview based on a cohort study. Int J Environ Res Public Health. https://doi.org/10.3390/ijerph14121543

30. Sarrel PM (2012) Women, work, and menopause. Menopause 19(3):250-252. https://doi.org/10.1097/gme.0b013e3182434e0c

Publisher's Note Springer Nature remains neutral with regard to jurisdictional claims in published maps and institutional affiliations. 